\title{
QUALIDADE DA ÁGUA DO RIBEIRÃO SÃO BARTOLOMEU AVALIADA PELO ÍNDICE DE QUALIDADE DA ÁGUA EM PONTO DE CAPTAÇÃO PARA ABASTECIMENTO NO PERÍODO SECO
}

\author{
G.L. MUNIZ
}

Universidade Estadual de Campinas

gustavolopesmuniz@yahoo.com.br

Artigo submetido 26/01/2017 e aceito em 24/10/2019

DOI: $10.15628 /$ holos.2019.5579

\section{RESUMO}

A qualidade da água captada para abastecimento desempenha papel significativo na seleção das tecnologias de tratamento, e pode ser determinada, de forma reduzida, através do Índice de Qualidade das Águas (IQA). Por meio do IQA, pode-se classificar os corpos hídricos em classes ou níveis de qualidade. Neste estudo, foi determinado o IQA em um ponto do ribeirão São Bartolomeu, no município de Viçosa-MG, especificamente, no reservatório de acumulação de água, localizado no campus da Universidade Federal de Viçosa (UFV), onde há captação da água por parte do Serviço Autônomo de Água e Esgotos (SAAE) para abastecimento de parte da zona urbana do município e captação por parte da UFV para abastecimento do campus. As amostras foram analisadas quanto aos parâmetros físicos, químicos e microbiológicos: $\mathrm{pH}$, turbidez, temperatura, oxigênio dissolvido, saturação de oxigênio, fósforo total, nitrogênio total, nitrato, demanda bioquímica de oxigênio (DBO), demanda química de oxigênio (DQO), condutividade elétrica, sólidos totais (ST), sólidos dissolvidos totais (SDT), sólidos suspensos totais (SST), sólidos sedimentáveis (SP), alcalinidade, coliformes totais e termotolerantes. As amostragens de água foram realizadas durante o período seco, de março a julho de 2016. A determinação do IQA permitiu classificar as águas do trecho onde ocorre a captação para abastecimento como de média qualidade, portanto, são apropriadas para tratamento convencional visando o abastecimento público. Das variáveis estudadas, apenas os SDT e a DBO não atenderam aos padrões estabelecidos na Resolução Conama 357/2005 para rios de classe 2 .

PALAVRAS-CHAVE: Tratamento de água, Recursos hídricos, Turbidez, Coliformes.

\section{SÃO BARTOLOMEU RIVERS WATER QUALITY EVALUETED BY WATER QUALITY INDEX AT CAPTATION PLACE TO SUPPLY IN DRY PERIOD}

\section{ABSTRACT}

The quality of the water collected for supply plays a significant role in the selection of treatment technologies. This quality can be determined in a reduced way through the Water Quality Index (IQA). Through IQA, water bodies can be classified into classes or levels of quality. In this study, the IQA was determined at a place in the São Bartolomeu river, in the city of Viçosa-MG, specifically in the reservoir of water accumulation, located on the campus of the Federal University of Viçosa (UFV), where has water collected by the Sewage and Water Autonomous Service (SAAE) to supply part of the urban area of the city and captation by the UFV to supply the campus. It was analyzed the physical, chemical and microbiological variables of the water: $\mathrm{pH}$, turbidity, temperature, dissolved oxygen, oxygen saturation, total phosphorus, total nitrogen, nitrate, biochemical oxygen demand (BOD), chemical oxygen demand (COD), electrical conductivity, total dissolved solids (SDT), total suspended solids (SST), sedimentable solids (SP), alkalinity, total coliforms and thermotolerant. Collects were undertaken during the dry period, from March to July 2016. The determination of the IQA allowed to classify the waters of the stretch, where occurs the capitation for supply, as of average quality, therefore, are appropriate for conventional treatment aiming for public supply. Among the studied variables only TDS and BOD not accorded to the standards established in resolution of CONAMA 357/2005 for rives class 2 .

KEYWORDS: Water treatment, Water resources, Turbidity, Coliforms. 


\section{INTRODUÇÃO}

A água desempenha um papel essencial na manutenção da saúde humana e do desenvolvimento sustentável dos ecossistemas (LU et al., 2015; SUN et al., 2016). O crescimento populacional, a urbanização e a industrialização, somados às mudanças nos padrões de consumo, geram demandas cada vez maiores de água doce em todo o mundo (BAGATIN et al., 2014).

O fornecimento de água representa um grande problema para as gerações futuras (VOROSMARTY et al., 2010). As mudanças no uso da terra relacionadas à agricultura, pecuária e urbanização contribuem para a deterioração da qualidade da água em todo o mundo (FOLEY et al., 2005); assim, a proteção e monitoramento das fontes de captação de água, principalmente as superficiais, é extremamente importante, por exemplo, para reduzir o risco de doenças associadas à água de má qualidade (PELEATO et al., 2017).

A manutenção da qualidade da água é um desafio, principalmente, devido à poluição de fontes pontuais e fontes não pontuais. A poluição por fontes pontuais inclui, entre outros, cargas de águas residuais industriais e domésticas, que podem ser identificadas com relativa facilidade (WANG et al., 2016). Ao contrário da poluição por fontes pontuais, a poluição por fontes não pontuais, geralmente, origina-se de fontes difusas, como a agricultura, o escoamento superficial e a deposição de poluentes atmosféricos (ONGLEY et al., 2010). As fontes de poluição, sejam elas pontuais ou difusas, contribuem para o aporte de nutrientes, matéria orgânica, patógenos e outros poluentes à água, deteriorando sua qualidade, o que acarreta no aumento dos custos de tratamento da mesma para as empresas responsáveis pelo abastecimento.

Conhecer a qualidade da água faz-se necessário para melhorar a previsão da contaminação da água em bacias hidrográficas não monitoradas e para fornecer diretrizes para o planejamento do uso da terra da bacia (SHI et al., 2017). Nesse aspecto, para caracterizar a qualidade da água, uma metodologia que pondera diversos parâmetros consiste no índice de qualidade da água (IQA), permitindo classificar os cursos d'água em classes ou níveis de qualidade (BILICH; LACERDA, 2005). O IQA é um índice de referência normalmente associado à qualidade da água bruta captada para o abastecimento público após o tratamento e sensível à contaminação por esgotos; assim, o IQA reflete a interferência por esgotos domésticos e outros materiais orgânicos, nutrientes e sólidos (IGAM, 2014).

O ribeirão São Bartolomeu faz parte da bacia do Rio Doce e localiza-se no município de Viçosa-MG. Em um trecho do ribeirão, localizado no campus da Uiversidade Federal de Viçosa (UFV), há um barramento de água, no qual, o Serviço Autônomo de Água e Esgotos (SAAE) e a UFV captam parte da água para abastecimento da cidade de Viçosa e do campus da UFV, respectivamente. De acordo com Dias (2007), o manancial encontra-se desprotegido da contaminação humana ou animal durante o seu curso até os pontos de captação de água, por parte do SAAE e da UFV, e percorrem áreas com intensa atividade agropecuária, expansão urbana, implantação de condomíneos e loteamento, fatores que podem interferir na qualidade da água. 
Ante o exposto, este estudo objetivou avaliar a qualidade da água do ribeirão São Bartolomeu, no período de ausência de chuvas (estação seca), no local onde ocorre a captação de água para fins de abastecimento e irrigação, através de variáveis físico-químicas e microbiológicas, e por meio do IQA.

\section{MATERIAL E MÉTODOS}

\subsection{Caracterização da área de estudo}

A bacia hidrográfica do ribeirão São Bartolomeu (Figura 1), que faz parte da bacia do Rio Doce, localiza-se no município de Viçosa, Zona da Mata do estado de Minas Gerais, localizado entre as coordenadas geográficas 4252'58" W e 4250'56" W de longitude e 2043'42" S e 2050'12" S de latitude, altitude média de 648 m (ARRUDA, 1997).

O clima da região, de acordo com a classificação de Köppen, é do tipo CWb sub-tropical de altitude mesotérmico e se caracteriza por verões chuvosos e brandos, com precipitação média anual de 1200 mm (CASTRO, 1983).

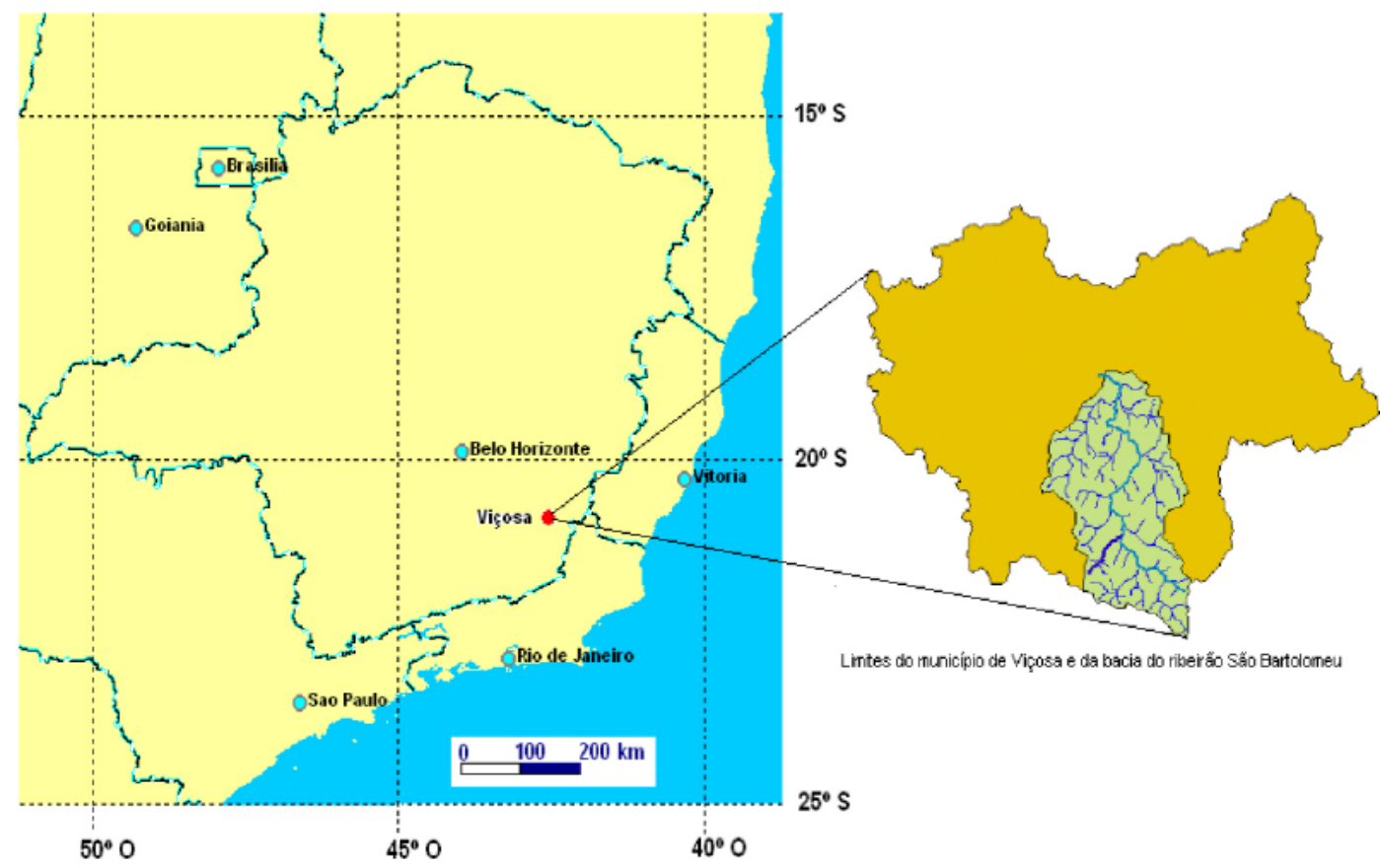

Figura 1: Bacia hidrográfica do ribeirão São Bartolomeu, município de Viçosa, Minas Gerais, Brasil.

Fonte: Costa et al. (2013)

A área estudada compreendeu o reservatório de acumulação (Figura 2), localizado no campus da Universidade Federal de Viçosa (UFV), onde há captação da água por parte do Serviço Autônomo de Água e Esgotos (SAAE) para abastecimento de parte da zona urbana do município e captação por parte da UFV para abastecimento do campus e irrigação de experimentos. $\mathrm{O}$ solo do entorno encontra-se parcialmente coberto por gramíneas e, conforme se observa na Figura 2, há 
presença de mata ciliar apenas em determinados pontos do ribeirão São Bartolomeu, não sendo suficiente para conter a ocorrência de processos erosivos quando há precipitação pluviométrica, sendo assim, quando há enxurradas, parte da água escoa e atinge o ribeirão, provocando alterações na qualidade da água local.

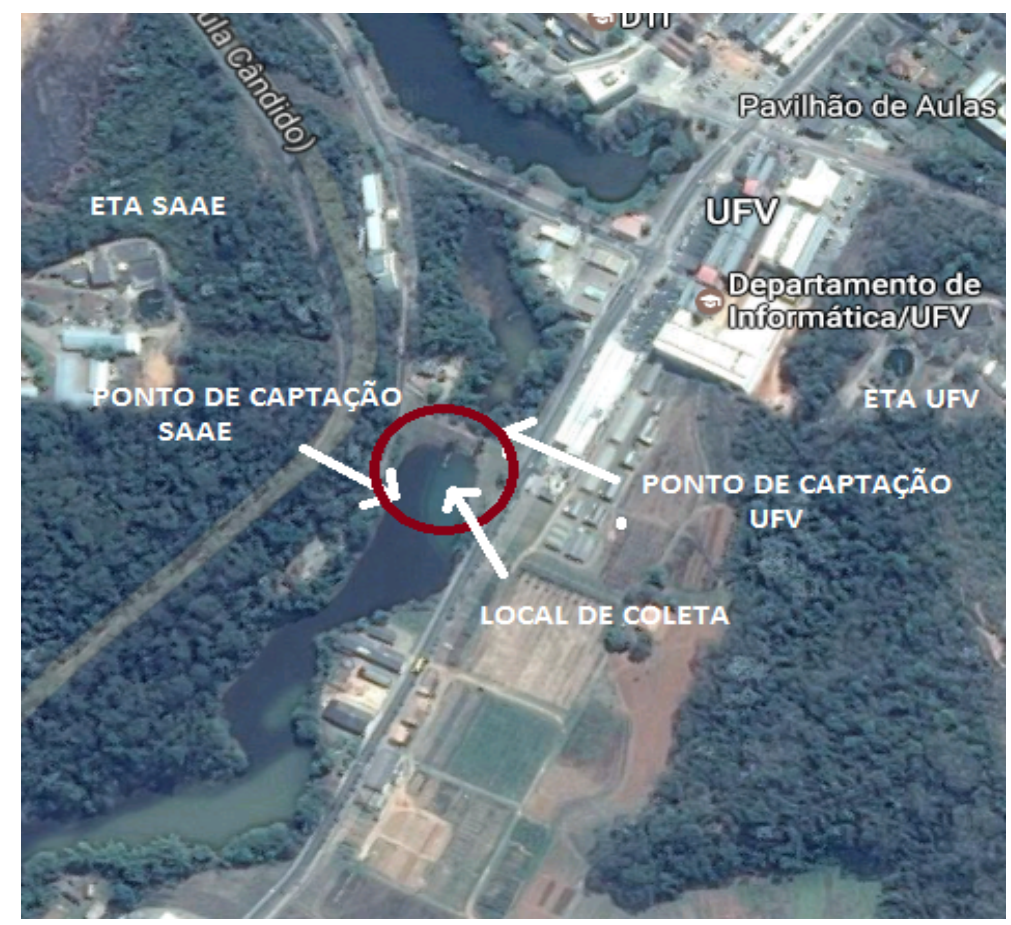

Figura 2: Trecho do ribeirão São Bartolomeu estudado. Pontos de captação por parte do SAAE e da UFV e local de coleta das amostras.

Fonte: Adaptado de Google Earth (2017).

\subsection{Amostragem}

As amostras foram coletadas no local onde ocorre a captação de água por parte do SAAE e da UFV (Figura 2). As coletas eram realizadas semanalmente durante o período de março a julho de 2016. As amostras foram armazenadas em garrafas esterilizadas de 2 L, de acordo com a NBR 9898, e transportadas para laboratório para análise das variáveis estudadas.

Embora se saiba que a qualidade da água varia em função da sazonalidade pluviométrica (SILVA; OLIVEIRA, 2014; KOLM et al., 2016; MEDEIROS et al., 2016) e que é importante conhecer a influência das chuvas na alteração das características físico-químicas e microbiológicas da água, não é objetivo desta pesquisa analisar a qualidade da água em período chuvoso para fins comparativos de resultados. Assim, este trabalho fica restrito à análise, discussão e entendimento da qualidade da água no ribeirão São Bartolomeu em período de seca, época em que a demanda de captação de água aumenta em função da ausência de chuvas.

\subsection{Determinações analíticas}


Quantificaram-se os valores de $\mathrm{pH}$, turbidez, temperatura, oxigênio dissolvido, saturação de oxigênio, fósforo total, nitrogênio total, nitrato, demanda bioquímica de oxigênio (DBO), demanda química de oxigênio (DQO), condutividade elétrica, sólidos totais (ST), sólidos dissolvidos totais (SDT), sólidos suspensos totais (SST), sólidos sedimentáveis (SP), alcalinidade, coliformes totais e termotolerantes, indicados pela E. Coli.

As análises foram realizadas no Laboratório de Qualidade da Água do Departamento de Engenharia Agrícola da UFV, seguindo-se metodologias apresentadas em APHA (2012).

\subsection{Análise dos dados}

Os resultados foram avaliados realizando-se a estatística descritiva (média e desvio padrão), de forma que os parâmetros analisados foram comparados com os limites estabelecidos pela Resolução Conama № 357 de 2005 (BRASIL, 2005), para os corpos de água doce de classe 2. Os parâmetros que não foram comparados é devido ao fato de que a resolução não estabelece padrões para os mesmos. Além disso, os parâmetros de monitoramento rotineiro no processo de tratamento de água foram comparados com a Portaria 2.914/2011 do Ministério da Saúde (BRASIL, 2011), que estabelece critérios para fins de potabilidade.

Parâmetros que são importantes na qualidade da água utilizada para irrigação foram confrontados com os valores padrões recomendados pela literatura (ARAGÜÉS et al., 1979; NAKAYAMA; BUCKS, 1986; AYERS; WESCOT, 1991; ALMEIDA 2010) para uso da água na irrigação, já que muito se utiliza da água captada pela UFV na irrigação de experimentos.

\subsection{Cálculo do índice de qualidade da água (IQA)}

Para avaliações da qualidade da água, foi utilizado o índice de qualidade de água (IQA), conforme IGAM (2012) e CETESB (2008), (Equação 1).

$$
\operatorname{IQA}=\prod_{i=1}^{\mathrm{n}} \mathrm{q}_{\mathrm{i}}^{\mathrm{w}_{\mathrm{i}}}
$$

em que,

IQA - índice de qualidade da água: um número entre 0 e 100;

$q_{i}$ - qualidade do i-ésimo parâmetro: um número entre 0 e 100, obtido da respectiva "curva média de variação de qualidade", em função de sua concentração ou medida;

$w_{i}$ - peso correspondente ao i-ésimo parâmetro: um número entre 0 e 1 , atribuído em função da sua importância para a conformação global de qualidade; e

$\mathrm{n}$ - número de parâmetros que entram no cálculo do IQA. 
O IQA foi calculado utilizando-se as variáveis: porcentagem de saturação de oxigênio dissolvido, Escherichia coli, $\mathrm{pH}, \mathrm{DBO}_{5}$, temperatura, nitrato, fosfato total, turbidez e resíduo total.

\section{RESULTADOS E DISCUSSÃO}

Todos os resultados aqui apresentados (Tabela 1) são das médias obtidas durante todo o período de amostragem seguidas do respectivo desvio padrão.

Tabela 1 - Valores médios dos parâmetros físico-químicos e microbiológicos analisados.

\begin{tabular}{c|c|c}
\hline Parâmetros & Valor médio & Desvio padrão \\
\hline $\mathrm{pH}$ & 6,70 & 0,10 \\
Condutividade elétrica $\left(\mu \mathrm{S} \mathrm{cm}^{-1}\right)$ & 97,68 & 0,36 \\
Temperatura $\left({ }^{\circ} \mathrm{C}\right)$ & 25,00 & 0,43 \\
Alcalinidade $\left(\mathrm{mg} \mathrm{L}^{-1} \mathrm{de} \mathrm{CaCO}_{3}\right)$ & 41,41 & 9,30 \\
Sólidos totais $\left(\mathrm{mg} \mathrm{L}^{-1}\right)$ & 510,00 & 13,44 \\
Sólidos dissolvidos totais $\left(\mathrm{mg} \mathrm{L}^{-1}\right)$ & 505,00 & 7,82 \\
Sólidos suspensos totais $\left(\mathrm{mg} \mathrm{L}^{-1}\right)$ & 5,00 & 1,08 \\
Sólidos sedimentáveis $\left(\mathrm{mL} \mathrm{L}^{-1}\right)$ & 0 & 0 \\
Turbidez $(\mathrm{UNT})$ & 9,87 & 0,60 \\
DBO $\left(\mathrm{mg} \mathrm{L}^{-1}\right)$ & 8,00 & 1,01 \\
DQO $\left(\mathrm{mg} \mathrm{L}^{-1}\right)$ & 39,60 & 4,84 \\
Oxigênio dissolvido $\left(\mathrm{mg} \mathrm{L}^{-1}\right)$ & 6,37 & 0,20 \\
Saturação de oxigênio $(\%)$ & $84^{*}$ & 0,20 \\
Nitrogênio total $\left(\mathrm{mg} \mathrm{L}^{-1}\right)$ & 0,03 & 0,01 \\
NO ${ }_{3}^{-}$- $\left(\mathrm{mg} \mathrm{L}^{-1}\right)$ & 0,13 & 0,07 \\
Fósforo total $\left(\mathrm{mg} \mathrm{L}^{-1}\right)$ & 0,02 & 0,02 \\
Coliformes totais $(\mathrm{NMP} / 100 \mathrm{~mL})$ & 53350 & 54,65 \\
E. coli (NMP/100 mL) & 400 & 0 \\
\hline
\end{tabular}

*Para o cálculo da saturação de oxigênio utilizou-se temperatura de 25으 e altitude de $664 \mathrm{~m}$.

\section{$3.1 \mathrm{pH}$}

A variação de $\mathrm{pH}$ depende das relações entre matéria orgânica, seres vivos, rocha, ar e água (ALVES et al., 2008). O pH da água, 6,7, encontra-se dentro dos limites estabelecidos pela Portaria 2.914/2011 do Ministério da Saúde, que estabelece valores entre 6,0 a 9,5 para que a água seja adequada ao consumo humano. Empresas que captam esta água, para abastecimento, a encontra com o valor de $\mathrm{pH}$ dentro dos limites estabelecidos por lei, minimizando os custos de tratamento. No entanto, vale ressaltar que o pH tem grande influência na floculação, devendo ser ajustado com produtos alcalinizantes, quando necessário, para que ocorra a formação de flocos. Portanto, o conhecimento do pH da água a ser tratada é fundamental. 
Verifica-se, ainda, que, o valor de $\mathrm{pH}$ encontra-se dentro dos limites estabelecidos pela Resolução Conama no 357/2005 para corpos de água doce de classe 2 (6,0 a 9,0). De acordo com Brasil (2014), para a adequada manutenção da vida aquática, o pH deve situar-se, geralmente, na faixa de 6 a 9, sendo que, seu valor contribui para um maior ou menor grau de solubilidade das substâncias, definindo o potencial de toxicidade de vários elementos. Águas com valores de pH alto tendem a provocar incrustações nas tubulações e equipamentos, já águas com baixo valor de $\mathrm{pH}$ tendem a ser corrosivas.

Para uso na irrigação é ideal que o pH da água esteja na faixa entre 6,5 a 8,4 (AYERS; WESTCOT, 1991); uma vez que esta água apresenta $\mathrm{pH}$ de 6,7 pode ser considerada propícia à irrigação, de acordo com a classificação de Ayers e Wescot (1991).

Lima et al. (2017) estudando a qualidade da água na sub-bacia do rio Cobras-RN encontraram valores de pH de 7,60 e 7,28 no fim do período da seca nos anos de 2009 e 2010, respectivamente. Já Alves et al. (2008), avaliando a qualidade da água da bacia do rio Pirapó em Maringá-PA, observaram que o $\mathrm{pH}$ variou de 7,2 a 8,4, valores superiores ao encontrado neste trabalho. $O$ valor do $\mathrm{pH}$, relativamente baixo, encontrado neste estudo pode ser decorrente da decomposição da matéria orgânica presente no curso d'água (O’NEILL, 1995), já que a DBO encontrada foi, razoavelmente, alta para corpos hídricos.

\subsection{Condutividade elétrica}

A condutividade elétrica da água é um parâmetro que deve ser monitorado, principalmente, quando a água for utilizada para irrigação pois, a partir do valor da condutividade elétrica, torna-se possível a estimativa da salinidade da água.

Conforme Almeida (2010), águas com condutividade elétrica entre 0 e $250 \mu \mathrm{S} \mathrm{cm}^{-1}$ são águas com baixa salinidade, podendo ser utilizadas para irrigação da maior parte dos cultivos e, em quase todos os tipos de solo. Portanto, a água do ribeirão São Bartolomeu possui baixa salinidade, uma vez que a condutividade elétrica da água foi de 97,68 $\mu \mathrm{S} \mathrm{cm}^{-1}$. Na Resolução Conama no 357 de 2005 não há referência em relação à condutividade elétrica, não cabendo aqui, classificação do ribeirão, segundo este parâmetro.

Ayers e Westcot (1991) afirmam que o grau de restrição do uso da água de irrigação quanto à condutividade elétrica é classificado como "nenhuma", quando os valores estiverem abaixo de 0,7

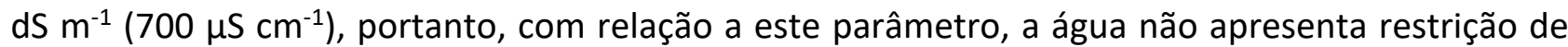
uso para irrigação. Resultados semelhantes a este foram encontrados por Meneghelli et al. (2016) avaliando a qualidade da água do rio Santa Maria do Doce-ES para fins de irrigação.

Lucas et al. (2010) estudando a qualidade da água na microbacia Rio Piracicaba-SP observaram que a condutividade elétrica da água no período seco variou entre 237 e $774 \mu \mathrm{S} \mathrm{cm}^{-1}$. Carvalho et al. (2004) observaram condutividade elétrica em torno de $0,06 \mathrm{mS} \mathrm{cm}^{-1}\left(60 \mu \mathrm{Sm}^{-1}\right)$ nas águas do ribeirão Ubá-MG, valor inferior ao encontrado neste trabalho. 


\subsection{Temperatura}

Embora a variação da temperatura da água seja um parâmetro para o cálculo do IQA, ressalta-se que, no âmbito do Programa Águas de Minas, para o cálculo do IQA considera-se o qi da variação de temperatura constante e igual a 92 (IGAM, 2014).

A alteração da temperatura da água pode ser causada por fontes antropogênicas ou naturais. De acordo com Brasil (2014), os ambientes aquáticos brasileiros apresentam, em geral, temperaturas entre 20 a $30^{\circ} \mathrm{C}$ e, em relação às águas para abastecimento, temperaturas elevadas aumentam as perspectivas de rejeição ao uso. A temperatura média do ribeirão São Bartolomeu, no ponto de amostragem, encontra-se na faixa comumente encontrada nos ambientes aquáticos brasileiros, uma vez que se situa na faixa entre 20 e $30^{\circ} \mathrm{C}$.

Miranda et al. (2009) estudando a qualidade dos recursos hídricos da Amazônia, especificamente, o Rio Tapajós, observaram que a temperatura média das águas era, aproximadamente, $29,7^{\circ} \mathrm{C}$. De acordo com estes autores, a temperatura é uma variável que depende da hora da coleta e da estação sazonal.

\subsection{Alcalinidade}

A alcalinidade da água é extremamente importante no processo de tratamento. De acordo com Brasil (2014), quando a alcalinidade natural é insuficiente na água a ser tratada, necessita-se adicionar alcalinizante, ajustando às necessidades da reação química.

Conforme os resultados apresentados, a água apresenta baixo valor de alcalinidade, 41,41 $\mathrm{mg} \mathrm{L}^{-1} \mathrm{em} \mathrm{CaCO}_{3}$, sendo a mesma devida à presença de bicarbonatos. $\mathrm{O}$ baixo valor de alcalinidade pode indicar que no local amostrado ocorre baixa decomposição da matéria orgânica e baixa taxa respiratória de microrganismos, com menor liberação e dissolução do gás carbônico na água.

Quanto aos critérios de potabilidade, conforme von Sperling (2014), a alcalinidade não tem significado sanitário, no entanto, altos valores de alcalinidade podem conferir gosto amargo para a água. Assim sendo, por apresentar baixo valor de alcalinidade, espera-se que a água analisada seja palatável.

De acordo com a classificação de Ayers e Westcot (1991), a restrição para o uso da água na irrigação ocorre a partir de valores de alcalinidade maiores que $425 \mathrm{mg} \mathrm{L}^{-1} \mathrm{em} \mathrm{CaCO}$. Portanto, em relação à alcalinidade, esta água não apresenta restrição para uso na irrigação.

Miranda et al. (2009) observaram que a água do Rio Tapajós apresentou alcalinidade média de 9,8 $\mathrm{mg} \mathrm{L}^{-1} \mathrm{em} \mathrm{CaCO}$, já, Pereira et al. (2007) encontraram alcalinidade de 6,9 $\mathrm{mg} \mathrm{L}^{-1} \mathrm{em} \mathrm{CaCO}_{3}$ no mesmo rio Tapajós, valores inferiores ao encontrado neste estudo.

\subsection{Sólidos}

HOLOS, Ano 35, v.7, e5579, 2019 
Conforme os resultados apresentados na Tabela 1, observa-se que, no local amostrado, a água possui baixa concentração de sólidos, sendo, a maior parte, constituída da fração dissolvida (SDT). Estes resultados justificam-se, uma vez que, águas superficiais, de maneira geral, apresentam baixas concentrações de sólidos, a não ser os corpos receptores de efluentes que possuem grandes quantidades de sólidos, o que não é o caso do local amostrado, já que, no local onde ocorre a captação de água, o ribeirão já sofreu o processo de autodepuração e a maior parte dos sólidos já se sedimentaram.

A ausência de sólidos sedimentáveis pode ser devido ao fato de que, no local onde a água está sendo captada, não há presença de regimes turbulentos, além de não haver grande aporte de sedimentos devido à erosão para o corpo hídrico, nem a presença de algas e outras substâncias sedimentáveis.

Quando comparado o valor de SDT aos limites estabelecidos pela Legislação, verifica-se que, a água, no ponto amostrado, atende à Portaria 2.914/2011 do Ministério da saúde, que estabelece limite máximo de $1000 \mathrm{mg} \mathrm{L}^{-1}$ de SDT na água para abastecimento humano, o que vem a minimizar os custos de tratamento nas ETAs. De acordo com Brasil (2014), esta parcela de sólidos reflete a influência de lançamentos de esgotos, além de afetar a qualidade organoléptica da água.

A Resolução Conama 357/2005 estabelece limite máximo de SDT de $500 \mathrm{mg} \mathrm{L}^{-1}$ em águas de classe 2, portanto, o ribeirão São Bartolomeu não atendeu à legislação, em relação a este parâmetro.

Lima et al. (2017) estudando a qualidade da água na sub-bacia do rio Cobras-RN encontraram valores de SDT no final do período seco de 138,23 e 491,58 mg L-1 nos anos de 2009 e 2010, respectivamente. Alves et al. (2008), à montante de um ponto de captação de água no rio Pirapó, observaram valores de ST variando de 100 a $310 \mathrm{mg} \mathrm{L}^{-1}$, de SST variando de 2 a $60 \mathrm{mg} \mathrm{L}^{-1}$ e de SDT variando de 100 a $250 \mathrm{mg} \mathrm{L}^{-1}$, além disso, os autores encontraram uma correlação entre os valores de SST e de turbidez nos pontos estudados.

Quanto ao uso da água para irrigação, Nakayama e Bucks (1986) classificam os valores de SST em baixo $\left(<50 \mathrm{mg} \mathrm{L}^{-1}\right)$, médio $\left(50-100 \mathrm{mg} \mathrm{L}^{-1}\right)$ e alto $\left(>100 \mathrm{mg} \mathrm{L}^{-1}\right)$ o risco de danos aos sistemas de irrigação. Dessa forma, o valor de SST encontrado neste trabalho apresenta baixo risco de danos aos sistemas de irrigação. Em relação aos SDT os mesmos autores classificam como baixo risco de entupimento quando a concentração de sólidos dissolvidos for menor que $500 \mathrm{mg} \mathrm{L}^{-1}$; moderado, quando estiver entre 500 e $2000 \mathrm{mg} \mathrm{L}^{-1}$, e severo, quando for maior que $2000 \mathrm{mg} \mathrm{L}^{-1}$. Visto que a concentração de SDT encontrada neste estudo foi de $505 \mathrm{mg} \mathrm{L}^{-1}$, esta água apresenta moderado risco de entupimento em relação a este parâmetro. No entanto, os valores de SDT em águas de irrigação usualmente utilizados estão entre 0 e $2000 \mathrm{mg} \mathrm{L}^{-1}$ (AYERS; WESCOT, 1991; ARAGUÉS, et al., 1979; ALMEIDA, 2010).

\subsection{Turbidez}


A turbidez é um dos principais parâmetros monitorados no tratamento de água. É devida aos sólidos suspensos presentes na água, assim sendo, uma baixa concentração de sólidos suspensos implica em uma baixa turbidez, afirmação que pode ser comprovada pelos resultados encontrados neste trabalho, já que, a baixa concentração de sólidos suspensos observada, de $5 \mathrm{mg}$ $\mathrm{L}^{-1}$, resultou em uma turbidez de apenas 9,87 UNT, abaixo do limite estabelecido pela Resolução Conama no 357/2005 para corpos de água doce de classe 2 (100 UNT).

O valor máximo de turbidez permitido na água para abastecimento é de 5 UNT, conforme a Portaria 2.914/2011 do Ministério da Saúde. Embora o valor de turbidez encontrado esteja acima de 5 UNT, segundo von Sperling (2014), águas brutas com valores de turbidez abaixo de 20 UNT podem ser dirigidas diretamente para a filtração lenta, dispensando a coagulação química, o que facilitaria e minimizaria os custos durante o tratamento.

O baixo valor de turbidez pode ser explicado devido à origem da água. Águas menos turbulentas apresentam valores de turbidez baixos, porém variável em função dos ventos e das ondas que podem revolver os sedimentos do fundo (KIM, 2011). Visto que há um barramento no ribeirão no local amostrado, feito para a captação de água, caracterizando o ambiente como lêntico, a sedimentação de partículas suspensas é favorecida, o que diminui a turbidez das águas.

Além disso, a amostragem foi feita durante o período seco, assim sendo, a qualidade da água não é influenciada pelos carreamentos de sedimentos devido às enxurradas, o que corrobora com os resultados encontrados neste trabalho.

Bonnet et al. (2008) avaliando a qualidade da água em bacias hidrográficas no estado de Goiás encontraram valores médios de turbidez de 8,72 UNT, no período seco; já Ribeiro et al. (2013) encontraram valores de turbidez de 6,11, 24,13 e 44,82 UNT, respectivamente, nos três pontos amostrados: $50 \mathrm{~m}$ à montante, $50 \mathrm{~m}$ e $500 \mathrm{~m}$ à jusante do ponto de lançamento do efluente no córrego Jurubatuba-GO.

\subsection{Demanda Bioquímica de Oxigênio $\left(\mathrm{DBO}_{5}\right)$}

A demanda bioquímica de oxigênio na água da lagoa da UFV foi de $8 \mathrm{mg} \mathrm{L}^{-1}$. Este resultado está de acordo com Matos (2011) pois, segundo o autor, em águas não poluídas, a $\mathrm{DBO}_{5}$ pode estar na faixa de 1 a $10 \mathrm{mg} \mathrm{L}^{-1}$, sendo os maiores valores encontrados em cursos d'água nos quais a matéria orgânica pode ser facilmente solubilizada. Visto que, no local onde foi feita a amostragem é rodeado por árvores e que, há grande aporte de folhas para o ribeirão, há maior quantidade de matéria orgânica em putrefação, aumentando, assim, o valor da DBO.

Além disso, o valor da DBO, relativamente alto, pode ser decorrente de lançamento de material orgânico à montante do ponto de coleta. Vale, porém, ressaltar que, a presença de microrganismos aeróbios presentes no local faz com que a matéria orgânica carbonácea esteja constantemente sendo degradada, diminuindo, com isso, o valor da DBO, que poderia ser maior.

Conforme a Resolução CONAMA 357 de 2005, o padrão de DBO para corpo d'água varia de acordo com as classes de enquadramento, ou seja, para rios de classe 1 , o valor máximo é de $3 \mathrm{mg}$ 
$\mathrm{L}^{-1}$, para rios de classes 2 e 3 é de 5 e $10 \mathrm{mg} \mathrm{L}^{-1}$, respectivamente, sendo que, para as últimas duas classes, o valor pode ser ultrapassado, com bases em estudo de autodepuração, caso a concentração de oxigênio dissolvido permaneça abaixo dos padrões da classe, nas condições críticas de vazão. Assim sendo, a água do ribeirão São Bartolomeu, no ponto amostrado, encontra-se fora das condições de classe 2 , com relação à DBO.

Alves et al. (2008) encontraram valor de DBO de 2,0 a 9,21 $\mathrm{mg} \mathrm{L}^{-1}$, apresentando, também, durante o período amostrado concentrações superiores ao limite estabelecido pela Resolução Conama no 357/2005 para corpos de água doce de classe 2. Ribeiro et al. (2013) estudando a qualidade da água do córrego Juruatuba observaram que, em pontos à jusante do lançamento de efluente, houve um aumento da DBO no período seco em razão do lançamento de efluente no córrego. Em todos os pontos amostrados por estes autores a DBO encontrada foi bem maior que a encontrada neste estudo.

\subsection{Demanda Química de Oxigênio (DQO)}

A concentração de matéria orgânica na água a ser tratada é de extrema importância, já que, o cloro, utilizado na desinfecção, pode complexar com a matéria orgânica em solução na água levando à formação de diversos subprodutos clorados, entre os quais os chamados trihalometanos, que são potencialmente cancerígenos (BRASIL, 2014).

O valor de DQO encontrado, 39,6 $\mathrm{mg} \mathrm{L}^{-1}$, está acima do encontrado por Ribeiro et al. (2013), que foi de $17,59 \mathrm{mg} \mathrm{L}^{-1}$ à montante de um ponto de lançamento de efluente no córrego Jurubatuba. Altos valores de DQO são encontrados, principalmente, em corpos receptores de efluentes que ainda não tenham passado pelo processo de autodepuração. Como no local em que as amostras foram coletadas não há pontos de lançamento de efluentes, acredita-se que a carga orgânica encontrada seja, sobretudo, de origem natural.

Carvalho et al. (2004), em todas as amostragens no ribeirão Ubá-MG, observaram que os valores de DQO aumentaram no sentido do escoamento do ribeirão Ubá na direção à cidade, chegando a encontrar valor igual a $749 \mathrm{mg} \mathrm{L}^{-1}$. A provável causa desse fato, de acordo com os mesmos autores, é a contribuição dos esgotos domésticos da cidade e de efluentes industriais de outras fábricas que são todos descartados no corpo do rio.

\subsection{Oxigênio Dissolvido (OD) e Porcentagem de Saturação de Oxigênio (PSO)}

Conforme von Sperling (2014), ao nível do mar, na temperatura de $20^{\circ} \mathrm{C}$, a concentração de saturação de oxigênio dissolvido é igual a 9,2 $\mathrm{mg} \mathrm{L}^{-1}$. Valores de oxigênio dissolvido superiores à saturação são indicativos da presença de algas, que pode ser um sinal de eutrofização do corpo hídrico. Já valores de oxigênio dissolvido bem inferiores à saturação são indicativos da presença de matéria orgânica, provavelmente esgotos (VON SPERLING, 2014). 
O valor de OD encontrado neste trabalho foi de $6,37 \mathrm{mg} \mathrm{L}^{-1}$, estando dentro dos padrões estabelecidos pela Resolução CONAMA 357/2005, que estabelece limite mínimo de $5 \mathrm{mg} \mathrm{L}^{-1}$ para rios de classe 2. Ribeiro et al. (2013) encontraram valor de OD no ribeirão Jurubatuba à montante do lançamento de efluentes de 5,94 $\mathrm{mg} \mathrm{L}^{-1}$, valor inferior ao encontrado neste trabalho. Pereira et al. (2007) em seu estudo químico ambiental do rio Murucupi em Barcarena-PA observaram que o OD estava em uma concentração de $5,1 \mathrm{mg} \mathrm{L}^{-1}$, valor também inferior ao obtido neste estudo.

Com relação à PSO, conforme a Embrapa (2011), águas que apresentam PSO menor que $60 \%$ é uma água pobre em oxigênio, a água pode estar muito quente ou as bactérias podem estar consumindo o OD; águas com PSO entre 60 e 79\% é aceitável para a maioria das espécies; águas com PSO entre 80 e 125\% é excelente para a maioria das espécies. Sendo assim, baseado no valor de PSO encontrado neste trabalho, pode-se concluir que, a água do ribeirão são Bartolomeu, no ponto de coleta, está em excelentes condições para a sobrevivência de peixes.

\subsection{Nitrogênio total $\left(N_{\text {total }}\right)$ e nitrato}

A concentração de $N_{\text {total }}$ e de nitrato na água observada foi de 0,03 e $0,13 \mathrm{mg} \mathrm{L}^{-1}$, respectivamente, valores inferiores aos observados por Ribeiro et al. (2013), que foi de 5,09 $\mathrm{mg} \mathrm{L}^{-1}$ de $\mathrm{N}$ e $6,41 \mathrm{mg} \mathrm{L}^{-1}$ de nitrato, $50 \mathrm{~m}$ à montante de um ponto de lançamento de efluente no córrego Jurubatuba. Mansor et al. (2006) observaram valor mínimo e máximo de concentração de nitrogênio total de 0,35 e 4,5 $\mathrm{mg} \mathrm{L}^{-1}$, respectivamente, ao avaliar a influência da atividade rural sobre a qualidade da água do rio Jaguari-SP.

A Resolução Conama 357/2005 estabelece limite máximo de nitrato para os rios de classe 2 de $10 \mathrm{mg} \mathrm{L}^{-1}$, a mesma resolução estabelece ainda que, para águas doces de classe 2, quando o nitrogênio for fator limitante para eutrofização, nas condições estabelecidas pelo órgão ambiental competente, o valor de nitrogênio total (após oxidação) não deverá ultrapassar $1,27 \mathrm{mg} \mathrm{L}^{-1}$ para ambientes lênticos. Portanto, o ribeirão São Bartolomeu, no trecho amostrado, encontra-se dentro dos padrões exigidos pela referida resolução para os rios de classe 2 , com relação aos parâmetros nitrogênio total e nitrato.

Os resultados aqui encontrados para $\mathrm{NO}_{3}^{-}-\mathrm{N}$ atende aos critérios de qualidade para uso na irrigação. Para a irrigação é ideal que a água apresente concentração de $\mathrm{NO}_{3}^{-}-\mathrm{N}$ entre 0 e $10 \mathrm{mg} \mathrm{L}^{-1}$ em termos de equivalente químico de N (AYERS; WESCOT, 1976, 1991; ARAGUÉS, et al., 1979; ALMEIDA, 2010). Conforme Almeida (2010), o conhecimento das concentrações de $\mathrm{N}$ na água de irrigação se faz necessário uma vez que pode haver desequilíbrios nutricionais, produzidos pelo excesso de nitrogênio ou desbalanço de elementos no solo.

\subsection{Fósforo total $\left(P_{\text {total }}\right)$}

De acordo com os resultados obtidos, verifica-se uma baixa concentração de fósforo total na água estudada. Este resultado mostra que a mesma se encontra nas condições de águas naturais 
não poluídas, conforme descrito por Matos (2011), já que a concentração de fósforo total na água está entre 0,01 e $0,05 \mathrm{mg} \mathrm{L}^{-1}$.

Os valores de fósforo na água variam conforme a época do ano. Slusarski et al. (2013), observaram que os teores de fósforo total em água são maiores nos meses de seca, devido a não ocorrência de chuva e, consequentemente, a concentração de fósforo aumenta, já que não vai haver o efeito da diluição. No entanto, conforme Valle Junior et al. (2010), em épocas chuvosas o teor de fósforo é maior devido a ocorrência de lixiviação de nutrientes para os cursos d'água. Portanto, há uma discrepância entre estes autores. Visto que, a determinação do fósforo na lagoa foi feita apenas em época da seca, não se pode dizer com qual dos autores os resultados estão condizentes, embora saiba-se que ambas as afirmações se justificam, cientificamente.

Em ambientes lênticos, como o do ribeirão estudado, os teores de fósforo são mais elevados, o que favorece o aparecimento de algas no local, uma vez que o fósforo é o fator limitante da eutrofização. Portanto, nesses locais, a concentração de $\mathrm{P}$ deve ser menor em relação aos ambientes lóticos e intermediários. Conforme a Resolução 357/2005 (BRASIL, 2005), a concentração de fósforo em ambientes lênticos para rios de classe 2 deve ser, no máximo, 0,03 $\mathrm{mg} \mathrm{L}^{-1}$ de $P$, verifica-se, com os resultados, que, no local amostrado, a água está com a concentração de $P$ dentro dos limites padrões para ambientes lênticos de classe 2.

Em termos de irrigação, a faixa usual de $\mathrm{PO}_{4}^{-3}-\mathrm{P}$ na água utilizada para irrigação é de 0 a 5 $\mathrm{mg} \mathrm{L}^{-1}$ em equivalente químico de $\mathrm{P}$ (AYERS; WESCOT, 1976, 1991; ARAGUÉS, et al., 1979; ALMEIDA, 2010), estando a água do ribeirão São Bartolomeu, no ponto amostrado, dentro da faixa indicada por estes autores.

Lucas et al. (2010), estudando a qualidade da água em uma microbacia hidrográfica Rio Piracicaba, SP, encontraram concentrações de fosfato variando entre 0,14 e 0,49 $\mathrm{mg} \mathrm{L}^{-1}$, maiores que a encontrada neste estudo.

\subsection{Coliformes totais e termotolerantes}

Os resultados mostraram elevado número do coliformes totais (Tabela 1). A detecção de coliformes totais em amostras de águas não é necessariamente um indicativo de contaminação fecal ou ocorrência de enteropatógenos (SOUZA, 2000). Portanto, mesmo a água apresentando elevados valores de coliformes totais, deve-se ater aos valores de coliformes termotolerantes, já que estes são um indicativo de contaminação fecal.

Os resultados aqui encontrados estão em conformidade com a literatura, já que é comum a detecção de coliformes totais em águas superficiais, como a do ribeirão estudado, uma vez que são águas não tratadas e sujeitas à poluição tanto por ação antrópica, quanto por ação da natureza e, dependendo das condições do corpo hídrico, o desenvolvimento e multiplicação desses microrganismos, torna-se favorável. Além disso, o grupo de coliformes totais inclui cerca de 20 espécies, dentre as quais encontram-se tanto bactérias originárias do trato gastrintestinal de humanos e outros animais homeotérmicos, como também diversos gêneros e espécies de bactérias 
não entéricas (SILVA et al., 2009), o que pode vir a ocorrer de forma natural em ambientes aquáticos.

Com relação ao NMP de coliformes termotolerantes encontrado, indicado pelo grupo $E$. Coli, observa-se que esta água pode apresentar problemas para a saúde pública pois, conforme Matos (2011), águas com presença de bactérias do grupo coliformes termotolerantes em contagem inferior a $180 \mathrm{NMP} / 100 \mathrm{~mL}$, parecem não apresentar problemas para a saúde pública. Do contrário, pode-se inferir que, água com $400 \mathrm{NMP} / 100 \mathrm{~mL}$, necessita-se de atenção, já que pode apresentar problemas para a saúde pública.

Quanto à balneabilidade, esta água não apresenta risco, já que está bem abaixo do valor indicado como referência pela Resolução Conama n 274 de 2000 (BRASIL, 2000), que é de 2300 $\mathrm{NMP} / 100 \mathrm{~mL}$. Para os demais usos, não deverá ser excedido um limite de 1.000 coliformes termotolerantes por 100 mililitros em $80 \%$ ou mais de pelo menos 6 (seis) amostras coletadas durante o período de um ano, com frequência bimestral (BRASIL, 2005). A Portaria 2.914 (BRASIL, 2011), estabelece que, águas destinadas ao consumo humano devem apresentar ausência de coliformes totais e $E$. coli em $100 \mathrm{~mL}$, portanto, a água do ribeirão São Bartolomeu que é captada para abastecimento necessita passar por tratamento químico convencional para a desinfecção, o que, de fato, ocorre.

\subsection{3 Índice de qualidade da água (IQA)}

Através dos resultados obtidos para as variáveis que compõem o IQA foi possível calculá-lo obtendo o valor de 68,86; assim, o nível da qualidade do ribeirão São Bartolomeu no ponto de amostragem é médio $(50<\mathrm{IQA} \leq 70)$, como pode ser visto na Tabela 2 . Águas com qualidade média são apropriadas para tratamento convencional visando o abastecimento público (CETESB, 2008; IGAM, 2012).

Tabela 2: Classificação da qualidade da água segundo o IQA

\begin{tabular}{c|c}
\hline Nível de Qualidade & Faixa \\
\hline Excelente & $90<$ IQA $\leq 100$ \\
Bom & $70<$ IQA $\leq 90$ \\
Médio & $50<$ IQA $\leq 70$ \\
Ruim & $25<$ IQA $\leq 50$ \\
Muito ruim & $00<$ IQA $\leq 25$ \\
\hline
\end{tabular}

Fonte: Adaptado de CETESB (2008) e IGAM (2012)

O IGAM (2014), monitorando as águas superficiais de MG em 2013, observaram que, ao longo da série histórica de monitoramento (1997 a 2013), houve predominância da classificação média (41 a 56\% de ocorrência) nos rios monitorados. Exceção foi observada em 2006, quando 
prevaleceu o IQA Bom, com 40\% de frequência. O IQA Excelente foi observado nos anos de 2004 a 2008 (1 a 2\% de ocorrência).

Diferente de Minas Gerais, no estado de São Paulo a CETESB atribui a seguinte classificação para o IQA: ótima (79 < IQA $\leq 100)$; boa $(51<\mathrm{IQA} \leq 79)$; regular $(36<\mathrm{IQA} \leq 51)$; ruim $(19<\mathrm{IQA} \leq 36)$ e péssima (IQA $\leq 19)$.

Zanini et al. (2010) estudando a qualidade da água da microbacia do córrego Rico -SP, em três diferentes pontos do córrego ( 1 - nascente, 2 - após o lançamento de efluentes e 3 - na captação de água do SAAEJ) obtiveram, no período seco, o IQA para os três pontos, respectivamente, de 76,55; 56,96 e 67,34, classificando-as como de boa qualidade, conforme a classificação proposta pela CETESB. De acordo com os mesmos autores, estes resultados estão coerentes com a localização dos pontos, pois o ponto 1 refere-se à região da nascente, local ainda preservado, enquanto o ponto 2 pode ter sido influenciado por fontes pontuais de contaminação (Estação de Tratamento de Esgotos e granja de suínos) e no ponto 3, após diluição e autodepuração ocorre melhor qualidade da água.

Baseado no resultado de IQA encontrado, verifica-se a necessidade de monitoramento da qualidade da água do ribeirão São Bartolomeu, disponibilizando, assim, mais informações a fim de garantir o gerenciamento sustentado dos recursos hídricos e fornecer subsídios para que medidas de manejo sejam tomadas, assegurando a qualidade das águas do ribeirão São Bartolomeu, já que, alterações na qualidade da água pode levar a prejuízos econômicos, como o aumento do custo de aquisição e tratamento da água do ribeirão. Ressalta-se, ainda, a importância de fiscalização do processo de uso e ocupação do solo no entorno do ribeirão São Bartolomeu, a fim de garantir a qualidade da água no reservatório.

\section{CONCLUSÃO}

Durante o período amostrado (período seco) verificou-se que, das variáveis estudadas, apenas os SDT e a DBO não atenderam aos padrões estabelecidos na Resolução Conama 357/2005 para rios de classe 2. Para fins de irrigação, a água do ribeirão São Bartolomeu, no ponto estudado, apresenta moderado risco de entupimento ao sistema, em relação à concentração de SDT, porém, a concentração está no intervalo usual na água destinada à irrigação.

A determinação do Índice de Qualidade das Águas do ribeirão São Bartolomeu permitiu classificar as águas do trecho onde ocorre a captação para abastecimento como de média qualidade. Assim, o conhecimento dos níveis de qualidade dos corpos hídricos que são utilizados como fonte de abastecimento é de extrema importância, uma vez que irá refletir diretamente nos custos de tratamento da água.

Faz-se necessário o monitoramento da qualidade da água também no período chuvoso, uma vez que o escoamento superficial é mais intenso, podendo diminuir a qualidade da água em função do aumento da concentração de poluentes ou, por outro lado, elevar a qualidade da água em períodos de cheias, em função do efeito da diluição de poluentes. 


\section{REFERÊNCIAS}

ALMEIDA, O. A. Qualidade da água de irrigação. Embrapa, Cruz das Almas: Embrapa mandioca e fruticultura, 2010.

ALVES, E. C.; SILVA, C. F.; COSSICH, E. S.; TAVARES, C. R. G.; SOUZA FILHO, E. E.; CARNIEL, A. Avaliação da qualidade da água da bacia do rio Pirapó - Maringá, Estado do Paraná, por meio de parâmetros físicos, químicos e microbiológicos. Acta Scientiarum Technology, v. 30, n. 1, p. 39-48, 2008.

APHA - AMERICAN PUBLIC HEALTH ASSOCIATION. Standard methods for the examination of water and wastewater. $22 \mathrm{ed}$. Washington: APHA, 2012, $1935 \mathrm{p}$.

ARAGUÉS, R.; ALBERTO, F.; CUCHI, J. A.; MANCHIN, J. Calidad de agua para riego. I: Criterios generales. Zaragoza: ITEA, p. 3-17, 1979.

ARRUDA, P. R. R. Uma contribuição ao estudo ambiental da Bacia Hidrográfica do Ribeirão São Bartolomeu, Viçosa, Minas Gerais. 108f. Dissertação (Mestrado em Ciência Florestal) -Universidade Federal de Viçosa, Viçosa-MG, 1997.

ASSOCIAÇÃO BRASILEIRA DE NORMAS TÉCNICAS (ABNT). NBR 9898: Preservação e técnicas de amostragem de efluentes líquidos e corpos receptores. ABNT, 23p., 1987.

AYERS, R. S.; WESTCOT, D. W. A qualidade da água na agricultura. Campina Grande: UFPB. 1991, 218p. Estudos FAO Irrigação e Drenagem, 29 revisado.

BAGATIN, R.; KLEME, S. J.; REVERBERI, A. P.; HUISINGH, D. Conservation and improvements in water resource management: a global challenge. Journal of Cleaner Production, v. 77, p. 1-9, 2014.

BILICH, M. R.; LACERDA, M. P. C. Avaliação da qualidade da água do Distrito Federal por meio de geoprocessamento. In: SIMPÓSIO BRASILEIRO DE SENSORIAMENTO REMOTO, 12., 2005, Goiânia. Anais... p. 2059-2.065.

BONNET, B. R. P.; FERREIRA, L. G.; LOBO, F. C. Relações entre qualidade da água e uso do solo em Goiás: Uma análise à escala da bacia hidrográfica. Revista Árvore, v. 32, p. 311-322, 2008.

BRASIL, Ministério da Saúde, Fundação Nacional de Saúde. Manual de controle da qualidade da água para técnicos que trabalham em ETAS - Brasília: Funasa, 2014.

BRASIL. Ministério da Saúde. Secretaria de Vigilância Sanitária. Portaria no. 2914 de 12 de dezembro de 2011. Dispõe sobre os procedimentos de controle e de vigilância da qualidade da água para o consumo humano e seu padrão de potabilidade. Diário Oficial da União, Brasília, 2011.

BRASIL. Resolução CONAMA. Conselho Nacional do Meio Ambiente no. 357 de 17 de março de 2005. Diário Oficial da República Federativa do Brasil, Brasília, DF, 2005. 23p.

CARVALHO, C. F.; FERREIRA, A. L.; STAPELFELDT, F. Qualidade das águas do ribeirão Ubá-MG. Revista Escola de Minas, v. 57, n. 3, p. 165-172, 2004.

CASTRO, P. S. Interceptação da chuva por mata natural secundária na região de Viçosa-MG. Revista Árvore, v. 7, n. 1, p. 76-89, 1983. 
COMPANHIA AMBIENTAL DO ESTADO DE SÃO PAULO - CETESB. Índices de Qualidade das Águas, Critérios de Avaliação da Qualidade dos Sedimentos e Indicador de Controle de Fontes: Apêndice B, Série Relatórios. 2008.

COSTA, T. A.; SOARES, V. P.; RIBEIRO, C. A. A. S.; GLERIANI, J. M. Conflitos de Uso da Terra na Microbacia do São Bartolomeu - Viçosa, MG. Floresta e Ambiente, v. 20, n. 3, p. 281-295, 2013.

DIAS, G. M. F. Qualidade microbiológica da água da bacia do Ribeirão São Bartolomeu, Viçosa-MG: análise epidemiológica, ambiental e espacial. 136f. Dissertação (mestrado em Medicina Veterinária) - Universidade Federal de Viçosa, Viçosa-MG, 2007.

EMBRAPA. Manual para formação e capacitação de grupos comunitários em metodologias participativas de monitoramento de qualidade da água - módulo III: avaliação físico-química / organizadores, Carlos Eduardo Siste, Enio Giuliano Girão, Bryan L. Duncan; tradução Ivan Vieira. Fortaleza: Embrapa Agroindústria Tropical, 2011.

FOLEY, J. A.; DEFRIES, R.; ASNER, G. P.; BARFORD, C.; BONAN, G.; CARPENTER, S. R.; CHAPIN, F. S.; COE, M. T.; DAILY, G. C.; GIBBS, H. K.; HELKOWSKI, J. H.; HOLLOWAY, T.; HOWARD, E. A.; KUCHARIK, C. J.; MONFREDA, C.; PATZ, J. A.; PRENTICE, I. C.; RAMANKUTTY, N.; SNYDER, P. K. Global consequences of land use. Science, v. 309, n. 5734, p.570-574, 2005.

INSTITUTO MINEIRO DE GESTÃO DAS ÁGUAS - IGAM. Monitoramento da qualidade das Águas Superficiais em 2012. Instituto Mineiro de Gestão das Águas. Belo Horizonte: IGAM, 2012. (Resumo executivo).

INSTITUTO MINEIRO DE GESTÃO DAS ÁGUAS - IGAM. Monitoramento das Águas Superficiais de Minas Gerais em 2013. Instituto Mineiro de Gestão das Águas. Belo Horizonte: IGAM, 2014. (Resumo executivo).

KIM, M. Estudo da variabilidade de turbidez no trecho superior no rio Guandu. 77f. Trabalho de conclusão de curso (Graduação em Engenharia Civil) - Universidade Federal do Rio de Janeiro, Rio de janeiro, 2011.

KOLM, H. E.; SIQUEIRA, A.; MACHADO, E. C. Influência da pluviosidade na qualidade da água de dois sangradouros do litoral do paraná, Brasil. Brazilian Journal of Aquatic Science and technology. V. 20, n. 2, p. 1-11, 2016.

LIMA, A. O.; LIMA-FILHO, F. P.; DIAS, N. S.; REGO, P. R. A.; BLANCO, F. F.; NETO, M. F. Mechanisms controlling surface water quality in the Cobras river sub-basin, Northeastern Brazil. Caatinga, v. 30, n. 1, p. 181-189, 2017.

LU, Y.; SONG, S.; WANG, R.; LIU, Z.; MENG, J.; SWEETMAN, A. J.; JENKINS, A.; FERRIER, R. C.; LI, H.; LUO, W.; WANG, T. Impacts of soil and water pollution on food safety and health risks in China. Environment International, v. 77, p. 5-15, 2015.

LUCAS, A. A. T.; FOLEGATTI, M. V.; DUARTE, S. Qualidade da água em uma microbacia hidrográfica Rio Piracicaba, SP. Revista Brasileira de Engenharia Agrícola Ambiental, v. 14, n. 9, p. 937-943, 2010. 
MANSOR, M. T. C.; TEIXEIRA FILHO, J.; ROSTON, D. M. Avaliação preliminar das cargas difusas de origem rural, em uma sub-bacia do rio Jaguari, SP. Revista Brasileira de Engenharia Agrícola e Ambiental, v. 10, p. 715-723, 2006.

MATOS, A. T. de. Qualidade do meio físico ambiental. Viçosa: AEAGRI. (Série Caderno Didático 33) 2011, 183p.

MEDEIROS, A. C.; LIMA, M. O.; GUIMARÃES, R. M. Avaliação da qualidade da água de consumo por comunidades ribeirinhas em áreas de exposição a poluentes urbanos e industriais nos municípios de Abaetetuba e Barcarena no estado do Pará, Brasil. Ciência e Saúde Coletiva, v. 21, n. 3, p. 695708, 2016.

MENEGHELLI, C. M.; LO MONACO, P. A. V.; CORREA, J. M.; BIRCHLER, R.; LOSS, J. B. Qualidade da agua do rio Santa Maria do Doce - Es para irrigação. Enciclopédia Biosfera, v. 13, n. 2, p. 279-289, 2016.

MIRANDA, R. G.; PEREIRA, S. F. P.; ALVES, D. T. V.; OLIVEIRA, G. R. F. Qualidade dos recursos hídricos da Amazônia - Rio Tapajós: avaliação de caso em relação aos elementos químicos e parâmetros físico-químicos. Ambi-Agua, v. 4, n. 2, p. 75-92, 2009.

NAKAYAMA, F. S.; BUCKS, D. A. Trickle irrigation for crop production. 1 St. Joseph: ASAE, 1986. 383p.

O’NEILL, P. Environmental chemistry. London: Champman and Hall, 1995.

ONGLEY, E. D.; XIAOLAN, Z.; TAO, Y. Current status of agricultural and rural non-point source pollution assessment in China. Environmental Pollution, v. 158, n. 5, p.1159-1168, 2010.

PELEATO, N. M.; LEGGE, R. L.; ANDREWS, R. C. Investigation of fluorescence methods for rapid detection of municipal wastewater impact of drinking water sources. Spectrochimica Acta Part A: Molecular and Biomolecular Spectroscopy, v. 171, p. 104-111, 2017.

PEREIRA, S. F. P.; LIMA, M. A.; FREITAS, K. H.; MESCOUTO, C. S.; SARAIVA, A. F. Estudo químico ambiental do rio Murucupi - Barcarena, PA, Brasil, área impactada pela produção de alumínio. Revista Ambi-Água, v. 2, n. 3, p. 62-82, 2007.

RIBEIRO, E. A.; SANDRI, D.; BOÊNO, J. A. Qualidade da água de córrego em função do lançamento de efluente de abate de bovino. Revista Brasileira de Engenharia Agrícola e Ambiental, v. 17, n. 4, p. 425-433, 2013.

SHI, PENG.; ZHANG, Y.; LI, Z.; LI, Z.; XU, G. Influence of land use and land cover patterns on seasonal water quality at multi-spatial scales. Catena, v. 152, p. 182-190, 2017.

SILVA, E. S.; OLIVEIRA, J, C. S. Avaliação da qualidade da água da Reserva Particular Natural (RPPN) Seringal Triunfo, Rio Araguari, Ferreira Gomes-ap-Brasil. Biota Amazonia, v. 4, n. 2, p. 28-42, 2014.

SILVA, L. M.; SOUZA, E. H., ARREBOLA, T. M.; JESUS, G. A. Ocorrência de um surto de hepatite A em três bairros do município de Vitória (ES) e sua relação com a qualidade da água de consumo humano. Ciências saúde coletiva, v. 14, n. 6, p. 2163-2167, 2009. 
SLUSARSKI, A. M.; AZEVEDO, C. K.; SILVA, D. A.; BARBOZA, A. M.; CARVALHO, A. C. S.; OlIVEIRA, E. F.; WEBER, O. L. S. Fósforo total em alguns corpos d'água do Pantanal mato-grossense. In: 53응 Congresso Brasileiro de Química. Anais... Rio de Janeiro, 2013. Disponível em: <http://www.abq.org.br/cbq/2013/trabalhos/5/3516-17025.html> Acesso em: 17 jun. 2016.

SOUZA, D. A. Desenvolvimento de metodologia analítica para determinação de multiresíduos de pesticidas em águas de abastecimento de São Carlos - SP. 109f. Dissertação (Doutorado em Ciências da Engenharia Ambiental) - Escola de Engenharia de São Carlos, Universidade de São Paulo, São Carlos, 2000.

SUN, Y.; CHEN, Z.; WU, G.; WU, Q.; ZHANG, F.; NIU, Z.; HU, H. Characteristics of water quality of municipal wastewater treatment plants in China: implications for resources utilization and management. Journal of Cleaner Production, v. 131, p. 1-9, 2016.

VALLE JÚNIOR, R. F.; ABDALA, V. L.; GUIDOLINI, J. F.; ALMEIDA, R. F.; SOUZA, M. A. S. C. Ortofosfato como parâmetro indicador de qualidade da água em diferentes pontos de coleta na Bacia do Rio Uberaba. Enciclopédia Biosfera, v. 6, n. 11, p. 1-6, 2010.

VON SPERLING, M. Introdução à Qualidade das Águas e ao Tratamento de Esgotos (Princípios do Tratamento Biológico de Águas Residuárias; vol. 1). Belo Horizonte: DESA-UFMG, 452p. 2014.

VOROSMARTY, C. J., MCINTYRE, P. B., GESSNER, M. O., DUDGEON, D., PRUSEVICH, A., GREEN, P., GLIDDEN, S., BUNN, S. E., SULLIVAN, C. A., LIERMANN, C. R., DAVIES, P. M. Global threats to human water security and river biodiversity. Nature, v. 467, n. 7315, p.555-561, 2010.

WANG, W.; LIU, X.; WANG, Y.; GUO, X.; LU, S. Analysis of point source pollution and water environmental quality variation trends in the Nansi Lake basin from 2002 to 2012. Environmental Science Pollution Research, v. 23, n. 5, p. 4886-4897, 2016.

ZANINI, H. L. H. T.; AMARAL, L. A.; ZANINI, J. R.; TAVARES, L. H. S. Caracterização da água da microbacia do córrego Rico avaliada pelo índice de qualidade de água e de estado trófico. Engenharia Agrícola, v. 30, n. 4, p. 732-741, 2010. 